\title{
An improved DNA marker technique for genetic characterization using RAMP-PCR with high-GC primers
}

\author{
C.L. Wei ${ }^{1,2 *}$, J.L. Cheng ${ }^{2 *}$, M.A. Khan ${ }^{2}$, L.Q. Yang ${ }^{2}$, S. Imani², \\ H.C. Chen ${ }^{3}$ and J.J. Fu $\mathbf{u}^{1,2,4}$ \\ ${ }^{1}$ State Key Laboratory of Quality Research in Chinese Medicine, \\ Macau University of Science and Technology, Macau (SAR), China \\ ${ }^{2}$ The Research Center for Preclinical Medicine, \\ Southwest Medical University, Luzhou, Sichuan Province, China \\ ${ }^{3}$ Department of Biochemistry, \\ School of Life Sciences \& the State Key Laboratory of Medical Genetics, \\ Central South University, Changsha City, Hunan Province, China \\ ${ }^{4}$ Judicial Authentication Center, Southwest Medical University, \\ Luzhou City, Sichuan Province, China \\ *These authors contributed equally to this study. \\ Corresponding author: J.J. Fu \\ E-mail: fujunjiang@hotmail.com / fujunjiang@swmu.edu.cn
}

Genet. Mol. Res. 15 (3): gmr.15038721

Received April 25, 2016

Accepted June 13, 2016

Published September 16, 2016

DOI http://dx.doi.org/10.4238/gmr.15038721

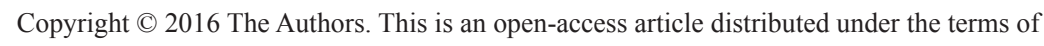
the Creative Commons Attribution ShareAlike (CC BY-SA) 4.0 License

\begin{abstract}
Random amplified polymorphic DNA (RAPD) is a widely used molecular marker technique. As traditional RAPD has poor reproducibility and productivity, we previously developed an improved RAPD method (termed RAMP-PCR), which increased the reproducibility, number of bands, and efficiency of studies on polymorphism. To further develop the efficiency of this method, we
\end{abstract}


used high-GC content primers for improved RAMP-PCR with DNA samples from Lonicera japonica. Comparison of amplification profiles obtained by standard RAPD primers with those obtained by regular PCR and RAMP-PCR, and high-GC primers with regular PCR and RAMPPCR showed that the average number of bands and polymorphisms per primer gradually and significantly increased (from 6.4 to 15.0 and from 4.6 to 10.2 , respectively). Cluster dendrograms showed similar results, indicating that this new method is consistent and reproducible. A total of 22 samples from different species, including plants, animals, and humans, were used for RAMP-PCR with high-GC primers. Multiple bands were successfully amplified from all samples, demonstrating that this method is a reliable technique with consistent results and may be of general interest in studies on different genera and species. We developed highly effective DNA markers, which can provide a more effective and potentially valuable approach than traditional RAPD for the genetic identification of various organisms, particularly of medicinal plants.

Key words: High-GC primer; RAMP-PCR; DNA marker; Random amplified polymorphic DNA; Genetic authentication

\section{INTRODUCTION}

Since the 1990s, the number of genetic- or DNA-based molecular marker techniques has increased. These include random amplified polymorphic DNA (RAPD) (Williams et al., 1990; Hess et al., 2000; Lima et al., 2011; Kumla et al., 2012; Fu et al., 2000, 2013; Shakeel et al., 2013; Lamine and Mliki, 2015), internal transcribed spacer (Hess et al., 2000; Varela et al., 2004; Pachuau et al., 2014), simple sequence repeat (Noormohammadi et al., 2013; Lamine and Mliki, 2015), inter-simple sequence repeat (ISSR) (Noormohammadi et al., 2013; Khadivi-Khub and Soorni, 2014), inter-retrotransposon amplified polymorphism (Noormohammadi et al., 2013), single primer amplification reaction (Satish et al., 2016), amplified fragment length polymorphism (Vos et al., 1995; Han et al., 2007; Khadivi-Khub and Soorni, 2014), and restriction fragment length polymorphism (Jeffreys et al., 1985; Tanksley et al., 1989) techniques. These techniques have been applied widely to various unicellular and multicellular organisms across different research areas. For example, they have been used alone or in combination with other markers for the assessment of genetic diversity and characterization of germplasms, identification and fingerprinting of genotypes, and molecular-assisted breeding (Agarwal et al., 2008; Fu et al., 2013; Shafiei-Astani et al., 2015 ) in studies on ecology, evolution, taxonomy, phylogeny, and genetics. RAPD markers alone or in combination with other markers are widely used for the genetic characterization of different species.

The RAPD technique is based on the amplification of genomic DNA (where the full genomic sequence is unknown) with single primers of 10-base nucleotide sequences. These primers detect polymorphisms in the absence of specific DNA sequences, and the polymorphisms function as genetic markers that can be used to construct genetic maps (Arif et al., 2010). The RAPD technique requires low concentrations of template DNA without any hazardous contamination, and is simple and inexpensive. However, it also has some

Genetics and Molecular Research 15 (3): gmr.15038721 
disadvantages such as poor reproducibility and low productivity (Williams et al., 1990; Fu et al., 2013; Mei et al., 2015a). However, the resolution and productivity of RAPD markers are greatly increased by prolonging the RAMP time between the annealing and extension stages in PCR (Fu et al., 2000, 2013; Mei et al., 2015a). Here, RAMP represents the stage between annealing and extension in the PCR amplification, whereas RAMP rate represents the rate of temperature increase during that period. RAMP-PCR is performed by extending the RAMP time from the annealing to the extension stage, or by decreasing the RAMP rate. This improved RAPD marker has been successfully applied alone or combined with other makers for the identification of several medicinal plants (Fu et al., 2013; Long et al., 2015; Mei et al., 2015a,b).

In this study, we aimed to develop a more effective DNA marker technique by using improved RAPD or RAMP-PCR with high-GC content primers, in which the GC-content reached 8-10 nucleotides in a 10-base oligonucleotide (oligos) length $(80-100 \%)$, which we termed "high-GC-RAMP-PCR". This will provide a potentially valuable approach for the genetic identification of various organisms.

\section{MATERIAL AND METHODS}

\section{RAPD primers and high-GC primers}

Standard 10-base oligos $(\mathrm{G}+\mathrm{C}$ content of $60-70 \%)$ used for RAPD have been previously described (Williams et al., 1990; Fu et al., 2013). Ten-base oligos with a highGC content (80-100\%) were designed and synthesized at Beijing DNA Chem. Biotechnology Co., Ltd. (Beijing, China). Oligos with 100\% GC content were further purified using highperformance liquid chromatography (HPLC) (Waters 2795, Waters Corporation, Milford, MA, USA), and the quality was subsequently examined by HPLC. Primer sequences with high-GC content are presented in Table 1.

Table 1. Sequences of high-GC primers.

\begin{tabular}{l|l|l|l}
\hline Name & Sequence & Name & Sequence \\
\hline FY-1 & CCAGCGCCCC & FY-13 & GCGTCCCGCC \\
\hline FY-2 & CTGCCGCCGC & FY-14 & CGTCCGCCGC \\
\hline FY-3 & CCGCCGCCGC & FY-25 & GTCGGCGGCG \\
\hline FY-4 & GCCCGCTGCC & FY-26 & GGTGCGCCGC \\
\hline FY-5 & CCAGCGTCCC & FY-27 & GCAGGCGGCG \\
\hline FY-6 & CCCGCGCCCC & FY-28 & CGAGCCCGCC \\
\hline FY-7 & GCCCGCCGCC & FY-29 & GCCGACCGGC \\
\hline FY-8 & CTGCCGCCAC & FY-30 & CCGCGCCCGC \\
\hline FY-9 & CAGCCGCCCC & FY-31 & CGTGGCCCCG \\
\hline FY-10 & GCTCCCGCCG & FY-32 & CGTGCCCGGC \\
\hline FY-11 & CCACCGCGCC & FY-33 & CTCGCGCCCC \\
\hline
\end{tabular}

\section{DNA preparation}

Lonicera japonica samples were obtained from different regions of Southern China, including Shenzhen in Guangdong Province, Yichang in Hubei Province, Leshan and Emei in Sichuan Province, and Loudi in Hunan Province, as described previously (Fu et al., 2013). DNA from leaf samples of L. japonica and other plant species was extracted using the cetyl trimethylammonium bromide method, with minor modifications (Fu et al., 2013). DNA from

Genetics and Molecular Research 15 (3): gmr.15038721 
samples of other animal species was extracted using the phenol/chloroform method (Fu et al., 2002, 2012). The 4T1 cell line used for DNA extraction has been previously described (Khan et al., 2015). The use of human and animal samples for DNA extraction was approved by the Ethics Committee of Southwest Medical University. Next, 1\% agarose gel electrophoresis and spectrophotometry were used to determine DNA quality. DNA samples were adjusted to a final concentration of $10 \mathrm{ng} / \mu \mathrm{L}$ and then stored at $-20^{\circ} \mathrm{C}$ until use (Fu, 2012; Fu et al., 2013, 2015).

\section{Amplification of DNA by RAPD-PCR}

PCR samples $(10 \mu \mathrm{L}$ total) were prepared as follows: $1 \mu \mathrm{L} 2.5 \mu \mathrm{M}$ primers, $1 \mu \mathrm{L}$ DNA template (10 ng) from L. japonica or other samples, $5 \mu \mathrm{L} 2 \mathrm{X}$ PCR Taq MasterMix (TianGen Biotech Co. Ltd., Beijing, China), and $3 \mu \mathrm{L}$ deionized $\mathrm{H}_{2} \mathrm{O}$. PCR conditions were as follows: initial denaturation at $95^{\circ} \mathrm{C}$ for $90 \mathrm{~s}$, followed by 40 cycles of $40 \mathrm{~s}$ at $94^{\circ} \mathrm{C}, 60$ $\mathrm{s}$ at $36^{\circ} \mathrm{C}, 90 \mathrm{~s}$ at $72^{\circ} \mathrm{C}$, and a final extension of $5 \mathrm{~min}$ at $72^{\circ} \mathrm{C}$ (Fu et al., 2013; Mei et al., 2015a). PCR amplification was performed in an Applied Biosystems Veriti ${ }^{\circledR}$ 96-Well Thermal Cycler (Life Technology, USA) (Fu et al., 2013; Mei et al., 2015a). For RAMP-PCR, the conditions were similar to those described, with the exception of different RAMP rates. The RAMP time between the annealing and extension stages at a RAMP rate of $5 \%\left(0.125^{\circ} \mathrm{C} / \mathrm{s}\right)$, $10 \%\left(0.25^{\circ} \mathrm{C} / \mathrm{s}\right), 20 \%\left(0.5^{\circ} \mathrm{C} / \mathrm{s}\right), 40 \%\left(1{ }^{\circ} \mathrm{C} / \mathrm{s}\right)$, and $100 \%\left(2.5^{\circ} \mathrm{C} / \mathrm{s}\right)$ were used in order to compare the efficiency and specificity in some L. japonica samples. The highest rate $(100 \%$, $2.5^{\circ} \mathrm{C} / \mathrm{s}$ ) was used as the default condition, termed 'regular PCR'. The RAMP rate between the annealing and extension stages was adjusted from $2.5^{\circ} \mathrm{C} / \mathrm{s}\left(100 \%\right.$ RAMP rate) to $0.125^{\circ} \mathrm{C} / \mathrm{s}$ (5\% RAMP rate) to compare the resolution and productivity of these two methods in all $L$. japonica samples with high-GC primers. Annealing temperatures of $30^{\circ}, 36^{\circ}$, and $42^{\circ} \mathrm{C}$ at a $5 \%$ RAMP rate were used to compare the efficiency and specificity of the reaction using highGC primers.

\section{Agarose gel electrophoresis}

The PCR-amplified products were resolved on a $1.5 \%$ agarose gel by electrophoresis in $1 \mathrm{X}$ Tris-acetate-EDTA buffer at $100 \mathrm{~V}$ for $50 \mathrm{~min}$. To increase the resolution, the electrophoresis was extended to $240 \mathrm{~min}$ at $60 \mathrm{~V}$ and $4^{\circ} \mathrm{C}$. Next, gels were stained with ethidium bromide $(0.5$ $\mu \mathrm{g} / \mathrm{mL}$ ). Bands were photographed using the ChemiDoc XR (Bio-Rad, USA) (Fu, 2012). The DL2000 DNA Marker, used in electrophoresis, was purchased from TaKaRa Biotechnology Co. Ltd. (Dalian, China). We selected unambiguous and reproducible bands in successive amplifications for scoring (Fu et al., 2013).

\section{Statistical analysis}

Bands in all gels from successive amplifications were documented as present (1) or absent (0) (Fu et al., 2013; Mei et al., 2015a). The similarity matrix and the similarity index were calculated using simple matching coefficient. The SAHN module in a NTSYS pc 2.1 package was used to generate dendrograms, which were based on an unweighted pair group method with arithmetic mean algorithm (UPGMA) (Rohlf, 2002; Fu et al., 2013).

Genetics and Molecular Research 15 (3): gmr.15038721 


\section{RESULTS}

\section{Establishment of a RAPD marker for DNA analysis using high-GC primers}

To increase the efficiency of RAPD amplification and to obtain more specific bands, high-GC content primers FY-10 and FY-13 were used to amplify DNA by adjusting the RAMP time at the stage between annealing $\left(36^{\circ} \mathrm{C}\right)$ and extension $\left(72^{\circ} \mathrm{C}\right)$ at a rate of $5 \%$ $\left(0.125^{\circ} \mathrm{C} / \mathrm{s}\right), 10 \%\left(0.25^{\circ} \mathrm{C} / \mathrm{s}\right), 20 \%\left(0.5^{\circ} \mathrm{C} / \mathrm{s}\right), 40 \%\left(1{ }^{\circ} \mathrm{C} / \mathrm{s}\right)$, and $100 \%\left(2.5^{\circ} \mathrm{C} / \mathrm{s}\right)$, using DNA samples from LD L. japonica. After electrophoresis using a $1.5 \%$ agarose gel, the number of amplified bands gradually increased with RAMP rates from 100 to 5\% (Figure 1a). The number of bands increased 5- to 7-fold with the high-GC primer FY-10, and 5- to 12-fold with the high-GC primer FY-13 (Figure 1a), when the RAMP rate decreased from 100 to $5 \%$. In addition, stronger band signals were observed at a RAMP rate of 5\% using these two primers, especially with primer FY-13. In the absence of a DNA template, no bands were observed at either RAMP rate (data not shown). Our results revealed that a decrease in the RAMP rate (especially at 5\%) significantly increased the number amplification products and subsequent bands. The annealing temperature commonly used in RAPD reactions is $\sim 36^{\circ}$, or $\sim 2^{\circ} \mathrm{C}$ higher than the average melting temperature of standard primers. The equivalent annealing temperature for $100 \% \mathrm{G}+\mathrm{C}$ or high-GC primers would be $\sim 42^{\circ} \mathrm{C}$. If an annealing temperature below the melting temperature accounts for the increased number amplification products observed with the high-GC primers, then increasing the temperature to $\sim 2^{\circ} \mathrm{C}$ above the melting temperature should lower the number of PCR products compared to those obtained using standard primers. Similarly, lowering the annealing temperature should increase the number of amplification products. To test this hypothesis, RAPD reactions utilizing a 5\% RAMP rate were performed with two DNA samples of L. japonica (Figure 1b) using the highGC primer FY-27 at annealing temperatures of $30^{\circ}, 36^{\circ}$, and $42^{\circ} \mathrm{C}$, respectively. Interestingly, raising the annealing temperature to $42^{\circ} \mathrm{C}$ and dropping it from $36^{\circ}$ to $30^{\circ} \mathrm{C}$ reduced the number of DNA fragments and bands generated from each sample (Figure 1b). These results suggest that an annealing temperature of $36^{\circ} \mathrm{C}$ is suitable for RAPD amplification. Further tests involving five other high-GC primers confirmed that an annealing temperature of $36^{\circ} \mathrm{C}$ would be better for RAPD amplification. Therefore, $36^{\circ} \mathrm{C}$ was selected as the annealing temperatures using high-GC primers for use in subsequent RAPD-PCR.

\section{Comparison of regular RAPD-PCR and RAMP-PCR with high-GC primers}

Regular RAPD-PCR (100\% RAMP rate) and RAMP-PCR (RAMP rate 5\%) were performed using all five L. japonica samples with different high-GC primers, including FY1, FY-13, and FY-25 to compare the efficiency of PCR amplification. Using primer FY-1, only 3-5 bands amplified from each sample by regular PCR (Figure 2a); however, the PCR products and number of amplified bands clearly increased (9-11) in RAMP-PCR (or improved RAPD) (Figure 2a). Using primer FY-13, 3-9 bands were amplified from each sample by regular PCR (Figure 2b), whereas the number of PCR products and DNA bands increased (81) by RAMP-PCR (Figure 2b). Using primer FY-25, 3-6 bands amplified from each sample by regular PCR (Figure 2c), but the levels of PCR products and DNA bands increased (6-8) by RAMP-PCR (Figure 2c, right panel). In addition, the signal intensities of the amplified bands at the matched position in the right panel were much stronger than those in the left panel

Genetics and Molecular Research 15 (3): gmr.15038721 
(Figure 2) with these three high-GC primers, demonstrating that more amplification products were generated by RAMP-PCR than by regular RAPD-PCR. Thus, the production, resolution, and reproducibility were significantly increased in RAMP-PCR by high-GC primers.
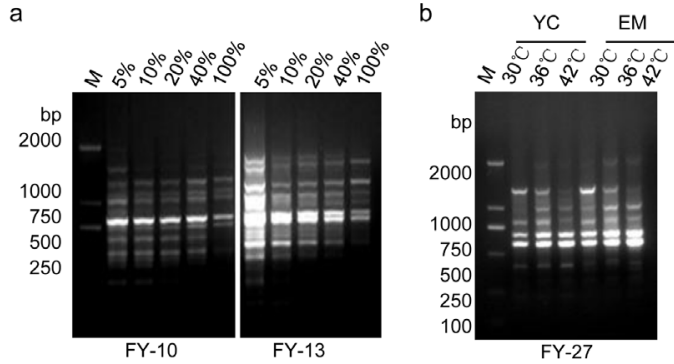

Figure 1. Efficiency of random amplification of polymorphic DNA (RAPD) PCR under different conditions. a. Comparison of different RAMP rates for RAPD PCR. Sample of Lonicera japonica from Loudi in Hunan Province was used for RAPD amplification using high-GC primers FY-10 (left) and FY-13 (right) at RAMP rates of 5, 10, 20,40 and $100 \%$, respectively. b. Efficiency of different annealing temperatures on high-GC primers. FY-27 primer was used to test the efficiency of different annealing temperatures 30,36 , and $42^{\circ} \mathrm{C}$, respectively, using L. japonica DNA samples from Yichang of Hubai Province (YC) (left) and Emei (EM) of Sichuan Province (right). Amplified PCR products were resolved by electrophoresis on a $1.5 \%$ agarose gel. Lane $M$ shows the DL2000 DNA marker with indicated molecular weight size $(\mathrm{bp})$.

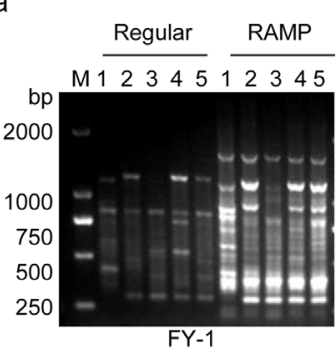

b

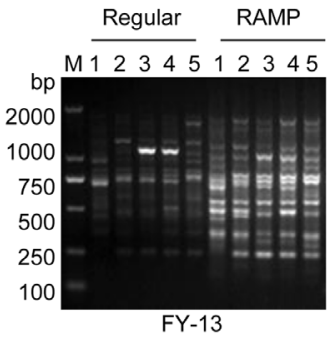

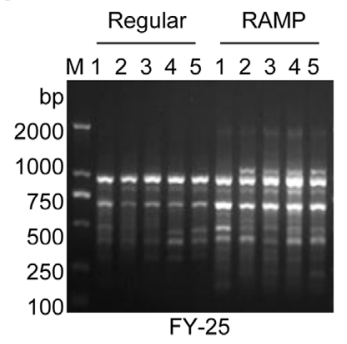

d
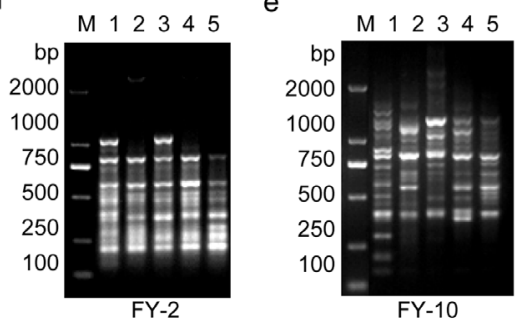

f

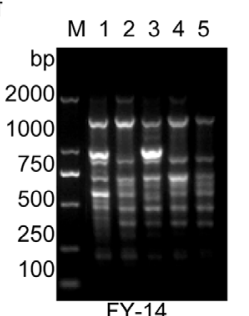

g

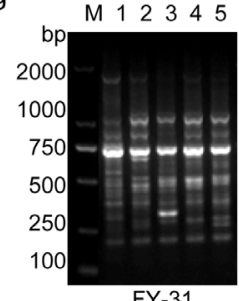

FY-31

Figure 2. Comparison between regular RAPD amplification and improved RAPD amplification with a 5\% RAMP rate using high-GC primers. a. Comparison using primer FY-1. b. Comparison using primer FY-13. c. Comparison using primer FY-25. Left panel indicates the results of regular RAPD amplification (regular PCR); right panel indicates the results of improved RAPD amplification (RAMP-PCR). d. e. f. g. Representative results of banding patterns in Lonicera japonica obtained by improved RAPD (5\% RAMP rate) with different high-GC primers. d. Primer FY-2. e. Primer FY-10. f. Primer FY-14. g. Primer FY-31. Lanes 1 to 5 represent different L. japonica samples presented in the order: Shenzhen of Guangdong Province, Yichang of Hubei Province, Leshan and Emei of Sichuan Province, and Loudi of Hunan Province. Lane $M$ represents DL2000 DNA marker with indicated molecular weight size (bp).

Genetics and Molecular Research 15 (3): gmr.15038721 


\section{Amplification of $L$. japonica samples using an improved RAPD marker with high-GC primers}

The improved RAMP/RAPD technique using high-GC primers was used to complete the amplification with other primers in all L. japonica DNA samples. A total of 22 high-GC primers (Table 1) produced reproducible polymorphic PCR bands when the improved RAPD amplification method was used (the representative results are shown in Figure 2d, e, f, and g). From 22 primers, a total of 346 bands were generated, and each primer obtained between 6 and 17 bands, with an average 15.04 bands per primer. The size of the DNA fragments ranged from 150 to $2500 \mathrm{bp}$. A total of $65 \%$ of the 346 generated bands were polymorphic and the average number of polymorphisms was 10.22 bands per primer.

The cluster dendrogram showed that the similarity coefficients among five L. japonica varieties ranged from 0.47 to 0.82 (Figure 3a). This is consistent with results previously obtained showing the similarity coefficients among five L. japonica varieties obtained by RAMP-PCR using standard primers (Fu et al., 2013) (Table 2).

Table 2. Comparison of primers with different GC-contents for regular or improved random amplification of polymorphic DNA (RAPD) analysis.

\begin{tabular}{l|c|c|c|c}
\hline Primer type (GC content) & \multicolumn{2}{|c|}{$60-70 \%$} & \multicolumn{2}{c}{$80-100 \%$} \\
\hline PCR type & Regular & RAMP & Regular & RAMP \\
\hline Total No. of primers used & 17 & 18 & 22 & 22 \\
\hline Total No. of amplified bands & 109 & 147 & 9.13 & 13 \\
\hline Average bands/primer & 6.41 & 8.16 & $1-12$ & 6.04 \\
\hline No. of bands detected/primer & $1-8$ & $3-11$ & 68.1 & 65 \\
\hline Total polymorphisms (\%) & 72.47 & 69 & 6.5 & 10.22 \\
\hline Average No. polymorphisms/primer & 4.647 & 5.63 & & \\
\hline
\end{tabular}

\section{Regular PCR with RAMP-PCR for standard RAPD primers, and regular PCR with RAMP-PCR for high-GC primers}

To compare regular PCR with standard RAPD primers, regular PCR with highGC primers was performed using five L. japonica samples (Figure $3 \mathrm{~b}$ and $\mathrm{c}$ ). The cluster dendrograms generated for regular PCR with standard RAPD primers, RAMP-PCR with standard RAPD primers, regular PCR with high-GC primers, and RAMP-PCR with high-GC primers are shown in Figure 3b, which was published in our previous study (Fu et al., 2013) (Figure $3 \mathrm{c}$ and a). The cluster dendrograms show that the results are similar with regular PCR and RAMP-PCR with standard RAPD primers, and regular PCR and RAMP-PCR with highGC primers using five L. japonica DNA samples.

The number of bands amplified per primer and polymorphisms detected using regular PCR and RAMP-PCR with standard RAPD primers, and with regular PCR and RAMP-PCR with high-GC primers are shown in Table 2. In regular PCR, 17 of 18 standard RAPD primers generated polymorphic bands, although primer SBS-I2 did not amplify well, whereas all 22 high-GC primers produced polymorphic bands in both regular PCR and RAMP-PCR. The total number of amplified bands obtained using regular PCR gradually increased with standard primers to RAMP-PCR with high-GC primers $(109,147,210$, and 346). The average number of bands per primer $(6.41,8.16,9.13$, and 15.04), and average number of polymorphisms per primer $(4.65,5.63,6.50$, and 10.22$)$ also gradually increased, respectively. Interestingly,

Genetics and Molecular Research 15 (3): gmr.15038721 
the total number of bands increased 2.35-fold, whereas both the average number of bands and average number of polymorphisms per primer increased almost 2-fold (1.84 and 1.815, respectively) when comparing high-GC primers with standard primers using RAMP-PCR. Furthermore, when high-GC primers in RAMP-PCR are compared with standard primers in regular PCR, the total number of bands increased 3.17-fold, where both the average number of bands and the average number of polymorphisms per primer increased more than 2-fold ( 2.35 and 2.20, respectively). Total polymorphisms (\%) were not significantly different $(72.47,69$, 68.1 , and 65 respectively) (Table 2).

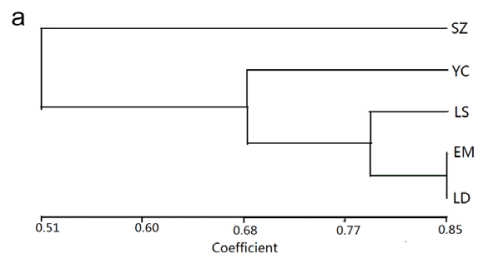

b

\begin{tabular}{llllll}
\hline No. & SZ & YC & LS & EM & LD \\
\hline SZ & 1 & & & & \\
YC & 0.468 & 1 & & & \\
LS & 0.513 & 0.734 & 1 & & \\
EM & 0.550 & 0.661 & 0.816 & 1 & \\
LD & 0.514 & 0.661 & 0.761 & 0.63 & 1 \\
\hline
\end{tabular}

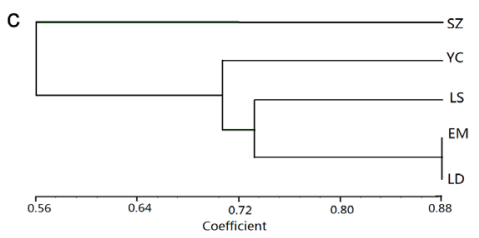

\begin{tabular}{clllll}
$\mathrm{d}$ & & & & & \\
\cline { 2 - 6 } No. & SZ & YC & LS & EM & LD \\
\hline SZ & 1 & & & & \\
YC & 0.598 & 1 & & & \\
LS & 0.565 & 0.734 & 1 & & \\
EM & 0.551 & 0.673 & 0.743 & 1 & \\
LD & 0.542 & 0.720 & 0.724 & 0.878 & 1 \\
\hline
\end{tabular}

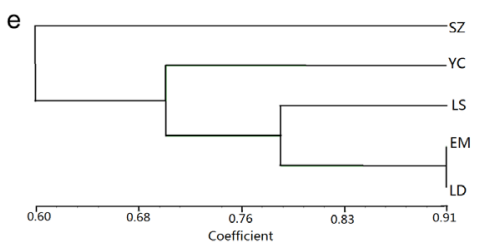

\begin{tabular}{llllll}
$f$ & & & & & \\
\hline No. & SZ & YC & LS & EM & LD \\
\hline SZ & 1 & & & & \\
YC & 0.609 & 1 & & & \\
LS & 0.615 & 0.692 & 1 & & \\
EM & 0.592 & 0.692 & 0.800 & 1 & \\
LD & 0.572 & 0.706 & 0.769 & 0.911 & 1 \\
\hline
\end{tabular}

Figure 3. Dendrogram of five Lonicera japonica samples subjected to different RAPD PCR conditiosn. a. b. Dendrogram of five $L$. japonica samples by regular RAPD PCR with standard primers. a. Dendrogram of five $L$. japonica samples. Bar on the bottom indicates the similarity index based on similarity matrix (SM) coefficients. b. Genetic distance dendrogram for $L$. japonica samples. c. d. Dendrogram of $L$. japonica samples using regular RAPD PCR with high-GC primers. c. Dendrogram of five L. japonica samples. Bar on the bottom indicates similarity index based on SM coefficients. d. Genetic distance dendrogram for $L$. japonica samples. e. f. Dendrogram of $L$. japonica samples using improved RAPD PCR with high-GC primers. e. Dendrogram of five $L$. japonica samples. Bar on the bottom indicates similarity index based on SM coefficients. f. Genetic distance dendrogram for $L$. japonica samples. Lanes 1 to 5 present the same order of samples as Figure 2.

\section{Use of improved RAPD analysis in different species using high-GC primers}

To test whether high-GC primers could be useful in different species, 22 samples including different medicinal plants (L. japonica, Dimocarpus longan, Chenopodium album, Ganoderma lucidum, Penthorum chinense, Penthorum sedoides, Dimocarpus confinis, Gardenia jasminoides, Livistona chinensis, Viola philippica, and Gastrodia elata), animals (rat), and human (normal DNA and cancer DNA), were used for RAMP-PCR with the FY-2 and FY-10 primers. The results showed that all samples amplified multiple bands (5-16) with 
the fragment sizes ranging from $\sim 200$ to $\sim 3000 \mathrm{bp}$ (Figure 4a). Comparison of regular RAPD and improved RAPD with a 5\% RAMP rate using samples from six different medicinal plant species with the high GC primers FY4 and FY5 showed that improved RAPD amplified more bands with higher productivity (Figure 4b).
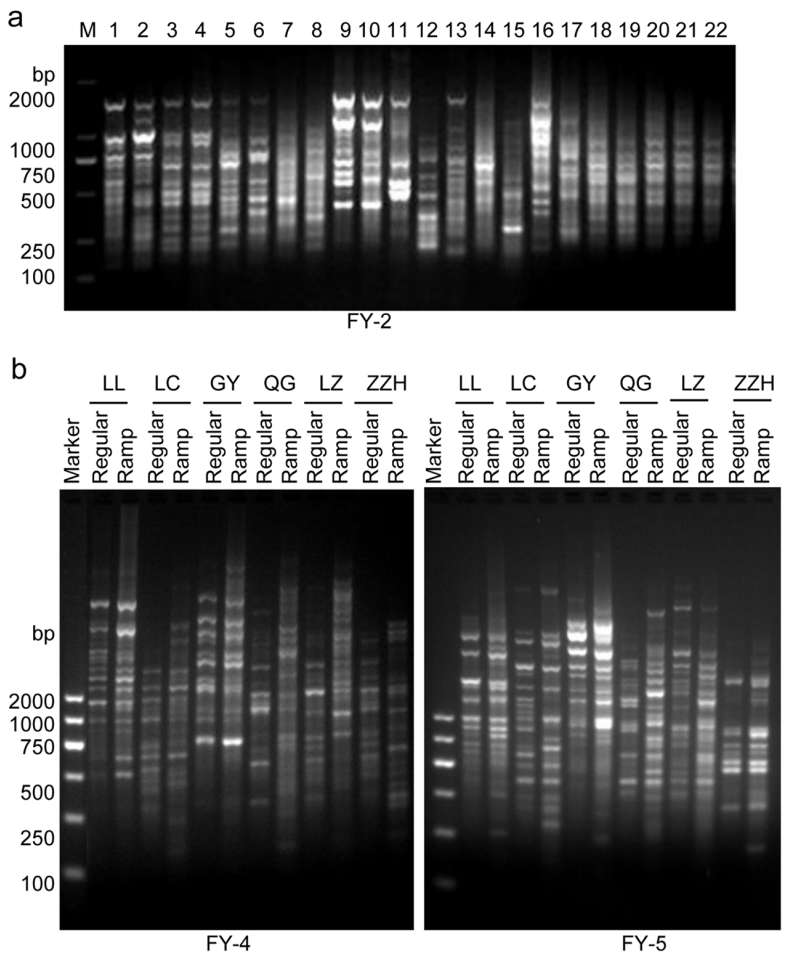

Figure 4. Improved RAPD PCR analysis of different species using high-GC primers. a. High-GC primer FY-2. Lanes 1 and 2 =Lonicera japonica from Guangdong and Sichuan, lanes 3 and $4=$ Dimocarpus longan from Guangdong and Guangxi, lanes 5 and $6=$ Canarium album from Sichuan and Fujian, lanes 7 and $8=$ Ganoderma tropicum (Jungh.) Bres and Ganoderma gibbosum (Blumii et Nees) Patouillard, lane $9=$ Penthorum chinense from Gulin County in Sichuan, lane 10= Penthorum sedoides, lane $11=$ Dimocarpus confinis, lane 12 = Gardenia jasminoides, lane $13=$ Litchi chinensis from Guangdong, lane $14=$ Viola philippica, lane $15=$ Gastrodia elata from Sichuan, lane 16= mouse 4T1 breast cancer cell line, lane $17=$ rat liver, lanes 18 and $19=$ white blood cells from male and female humans, respectively, lanes 20 and $21=$ normal female breast tissue and cancer tissue, lane 22 = HEK293 cells. b. Comparison of regular RAPD and improved RAPD (5\% RAMP rate) using samples from different species and high GC primers FY-4 (left) and FY-5 (right). LL is D. confinis, LC is L. chinensis, GY is $D$. longan, QG is C. album, LZ is G. lucidum, and ZZH is G. jasminoides. Lane M represents DL2000 DNA marker.

\section{DISCUSSION}

Analysis of genetic variation will help us to understand the molecular basis of different biological phenomena in medicinal plants (Agarwal et al., 2008). Since genomic sequencing projects have not yet been applied across the entire plant and animal kingdoms, the development of molecular markers and information on their associations with phenotypes should enable us to elucidate genetic variation or polymorphism. Advanced markers tend to incorporate the advantages of several basic techniques (Hess et al., 2000; Agarwal et al., 
2008; Kumla et al., 2012; Fu et al., 2013; Khadivi-Khub and Soorni, 2014). Newer methods might also incorporate improvements in the methodology of basic techniques to increase the sensitivity, repeatability or reproducibility, and resolution to monitor genetic discontinuity and distinctiveness (Fu et al., 2000; Hess et al., 2000; Agarwal et al., 2008; Kumla et al., 2012; Fu et al., 2013; Khadivi-Khub and Soorni, 2014). The RAPD technique has been widely used for the genetic identification of different organisms since 1990 (Williams et al., 1990). An improved RAPD technique using an extended RAMP time has been previously described by us. This technique was found to increase band numbers, repeatability, and DNA production (Fu et al., 2000), which was confirmed by ISSR (Fu et al., 2013; Mei et al., 2015b,c; Long et al., 2015). In the present study, we used high-GC primers, which are 10 oligos long and have a GC content of $80-100 \%$ to further increase the RAPD band specificity and amplification efficiency.

The FY-10 and FY-13 primers were used to amplify DNA by adjusting the RAMP time at the stage between annealing and extension at rates of $5 \%\left(0.125^{\circ} \mathrm{C} / \mathrm{s}\right), 10 \%\left(0.25^{\circ} \mathrm{C} / \mathrm{s}\right)$, $20 \%\left(0.5^{\circ} \mathrm{C} / \mathrm{s}\right), 40 \%\left(1{ }^{\circ} \mathrm{C} / \mathrm{s}\right)$, and $100 \%\left(2.5^{\circ} \mathrm{C} / \mathrm{s}\right)$, to optimize the technique. The $5 \% \mathrm{ramp}$ rate was found to significantly increase the number of bands and products. Next, primer FY-27 was used at annealing temperatures of $30^{\circ}, 36^{\circ}$, and $42^{\circ} \mathrm{C}$ to test the efficiency of RAMPPCR. Interestingly, either raising the annealing temperature to $42^{\circ} \mathrm{C}$ or dropping it to $30^{\circ} \mathrm{C}$ from $36^{\circ} \mathrm{C}$ reduced the number of DNA fragments and band-signal intensities generated from both samples. These results indicate that the increased numbers of RAPD-PCR products or signals obtained with the high-GC primers is not due to increased tolerance for mismatches at these annealing temperatures. These results also suggest that $36^{\circ} \mathrm{C}$ is the optimum annealing temperature for RAPD-PCR. Therefore, DNA fingerprints and cluster dendrograms can be obtained using high-GC primers with improved RAPD amplification. However, the molecular mechanism accounting for the increased amplification efficiency with the high-GC primers remains unknown. This may be due to the existence of a higher GC content across the whole genome of these plants and/or stronger binding ability of the primers resulting from three hydrogen bonds between $\mathrm{G}$ and $\mathrm{C}$, instead of two between $\mathrm{A}$ and $\mathrm{T}$.

To compare the consistency and efficiency, PCR amplification by regular RAPD with standard primers, RAMP-PCR with standard primers, regular RAPD with high GC primers, and RAMP-PCR with high-GC primers were performed. Cluster dendrograms showed similar results to those previously reported (Fu et al., 2013), which indicate that our newly developed method of improved RAPD with high GC primers is consistent. Interestingly, in addition to the increased yield of PCR products, the total number of amplified bands and average number of polymorphic bands per primer increased significantly (Table 2). These results indicate that high-GC content primers significantly increased band number, specific bands, and amplification efficiency in RAPD. Although high-GC primers by regular RAPD also generate an increased number of PCR products in a wide variety of other fungi, they do not appear to generate the same results in other species, for example, soybean and wheat DNA (Williams et al., 1990; Kubelik and Szabo, 1995). Thus, to further demonstrate whether the method of improved RAPD with high-GC primers is an important approach for different species, 18 samples, including medicinal plants, animals, and humans were used for RAMP-PCR with the high-GC primers FY-2 and FY-10, and multiple bands were successfully amplified from all samples. The comparison of regular RAPD and improved RAPD using six different plant species with the high GC primers FY-4 and FY-5 showed that improved RAPD amplified more bands and generated more DNA. Thus, we have developed a useful approach for the genetic

Genetics and Molecular Research 15 (3): gmr.15038721 
identification of species of plants and animals in different genera that are of general interest by using improved RAPD analysis with high-GC content primers. A previous study reported that regular RAPD analysis with high-GC primers only amplified well in some plants (Kubelik and Szabo, 1995). Here, we refer to this effective DNA marker technique utilizing improved RAPD with high-GC content primers as "high GC-RAMP-PCR". This method may also be very useful for developing sequenced characterized amplified region marker markers using high GC-RAMP-PCR (Cheng et al., 2016).

We developed effective DNA markers by using RAMP-PCR with high-GC content primers (high GC-RAMP-PCR), which may provide a potentially valuable approach for the identification of various unicellular and multicellular organisms, particularly medicinal plants.

\section{Conflicts of interest}

The authors declare no conflict of interest.

\section{ACKNOWLEDGMENTS}

Research supported, in part, by the National Natural Science Foundation of China (\#81172049), the Science and Technology Innovation Team of Colleges and Universities of Sichuan Province (\#13TD0032), the Applied Basic Research Program of Science and Technology Department of Sichuan Province (\#14JC0797 and \#2015JC038), and Southwest Medical University Foundation (\#2014QN091). The authors particularly thank all individuals who provided plant leaves or DNA samples.

\section{REFERENCES}

Agarwal M, Shrivastava N and Padh H (2008). Advances in molecular marker techniques and their applications in plant sciences. Plant Cell Rep. 27: 617-631. http://dx.doi.org/10.1007/s00299-008-0507-z

Arif IA, Bakir MA, Khan HA, Al Farhan AH, et al. (2010). A brief review of molecular techniques to assess plant diversity. Int. J. Mol. Sci. 11: 2079-2096. http://dx.doi.org/10.3390/ijms11052079

Cheng JL, Li J, Qiu YM, Wei CL, et al. (2016). Development of novel SCAR markers for genetic characterization of Lonicera japonica from high GC-RAMP-PCR and DNA cloning. Genet. Mol. Res. 15: http://dx.doi.org/10.4238/ gmr.15027737.

Fu J, Li L, Xu X, Wang Z, et al. (2000). An improved method for increasing the efficiency of the technique of random amplified polymorphic DNA (RAPD). Hereditas 22: 251-252.

Fu J, Li L and Lu G (2002). Relationship between microdeletion on Y chromosome and patients with idiopathic azoospermia and severe oligozoospermia in the Chinese. Chin. Med. J. (Engl.) 115: 72-75.

Fu J, Yang L, Khan MA and Mei Z (2013). Genetic characterization and authentication of Lonicera japonica Thunb. by using improved RAPD analysis. Mol. Biol. Rep. 40: 5993-5999. http://dx.doi.org/10.1007/s11033-013-2703-3

Fu JJ (2012). Short protocols in medical molecular biology. China Medical Science Press, Beijing

Fu JJ, Mei ZQ, Tania M, Yang LQ, et al. (2015). Development of RAPD-SCAR markers for different Ganoderma species authentication by improved RAPD amplification and molecular cloning. Genet. Mol. Res. 14: 5667-5676. http:// dx.doi.org/10.4238/2015.May.25.19

Han J, Zhang W, Cao H, Chen S, et al. (2007). Genetic diversity and biogeography of the traditional Chinese medicine, Gardenia jasminoides, based on AFLP markers. Biochem. Syst. Ecol. 35: 138-145. http://dx.doi.org/10.1016/j. bse.2006.05.021

Hess J, Kadereit JW and Vargas P (2000). The colonization history of Olea europaea L. in Macaronesia based on internal transcribed spacer 1 (ITS-1) sequences, randomly amplified polymorphic DNAs (RAPD), and intersimple sequence repeats (ISSR). Mol. Ecol. 9: 857-868. http://dx.doi.org/10.1046/j.1365-294x.2000.00942.x

Jeffreys AJ, Wilson V and Thein SL (1985). Individual-specific 'fingerprints' of human DNA. Nature 316: 76-79. http://

Genetics and Molecular Research 15 (3): gmr.15038721 
dx.doi.org/10.1038/316076a0

Khadivi-Khub A and Soorni A (2014). Comprehensive genetic discrimination of Leonurus cardiaca populations by AFLP, ISSR, RAPD and IRAP molecular markers. Mol. Biol. Rep. 41: 4007-4016. http://dx.doi.org/10.1007/s11033-014$\underline{3269-4}$

Khan MA, Tania M, Wei C, Mei Z, et al. (2015). Thymoquinone inhibits cancer metastasis by downregulating TWIST1 expression to reduce epithelial to mesenchymal transition. Oncotarget 6: 19580-19591. http://dx.doi.org/10.18632/ oncotarget.3973

Kubelik AR and Szabo LJ (1995). High-GC primers are useful in RAPD analysis of fungi. Curr. Genet. 28: 384-389. http://dx.doi.org/10.1007/BF00326438

Kumla S, Doolgindachbaporn S, Sudmoon R and Sattayasai N (2012). Genetic variation, population structure and identification of yellow catfish, Mystus nemurus (C\&V) in Thailand using RAPD, ISSR and SCAR marker. Mol. Biol. Rep. 39: 5201-5210. http://dx.doi.org/10.1007/s11033-011-1317-x

Lamine M and Mliki A (2015). Elucidating genetic diversity among sour orange rootstocks: a comparative study of the efficiency of RAPD and SSR markers. Appl. Biochem. Biotechnol. 175: 2996-3013. http://dx.doi.org/10.1007/ $\underline{\text { s12010-015-1477-6 }}$

Lima ATB, de Souza VAB, Gomes RLF and Lima PSC (2011). Molecular characterization of cajá, Spondias mombin (Anacardiaceae), by RAPD markers. Genet. Mol. Res. 10: 2893-2904. http://dx.doi.org/10.4238/2011.November.25.1

Long Y, Cheng J, Mei Z, Zhao L, et al. (2015). Genetic analysis of litchi (Litchi chinensis Sonn.) in southern China by improved random amplified polymorphic DNA (RAPD) and inter-simple sequence repeat (ISSR). Mol. Biol. Rep. 42: 159-166. http://dx.doi.org/10.1007/s11033-014-3755-8

Mei Z, Khan MA, Yang L, Yang M, et al. (2015a). Genetic characterization and authentication of Gardenia jasminoides in different regions of China by using improved RAPD analysis. Indian J. Exp. Biol. 53: 164-169.

Mei Z, Zhang C, Khan MA, Zhu Y, et al. (2015b). Efficiency of improved RAPD and ISSR markers in assessing genetic diversity and relationships in Angelica sinensis (Oliv.) Diels varieties of China. Electron. J. Biotechnol. 18: 96-102. http://dx.doi.org/10.1016/j.ejbt.2014.12.006

Mei Z, Zhou B, Wei C, Cheng J, et al. (2015c). Genetic authentication of Gardenia jasminoides Ellis var. grandiflora Nakai by improved RAPD-Derived DNA markers. Molecules 20: 20219-20229. http://dx.doi.org/10.3390/ molecules201119687

Noormohammadi Z, Hasheminejad-Ahangarani Farahani Y, Sheidai M, Ghasemzadeh-Baraki S, et al. (2013). Genetic diversity analysis in Opal cotton hybrids based on SSR, ISSR, and RAPD markers. Genet. Mol. Res. 12: 256-269. http://dx.doi.org/10.4238/2013.January.30.12

Pachuau L, Atom AD and Thangjam R (2014). Genome classification of Musa cultivars from northeast India as revealed by ITS and IRAP markers. Appl. Biochem. Biotechnol. 172: 3939-3948. http://dx.doi.org/10.1007/s12010-014-0827-0

Rohlf FJ (2002). NTSYS-pc: numerical taxonomy system ver.2.1, Exeter Pub. Ltd., Setauket, New York, Available: http:// www.exetersoftware.com/cat/ntsyspc/ntsyspc.html. Accessed 6 July 2015.

Satish L, Shilpha J, Pandian S, Rency AS, et al. (2016). Analysis of genetic variation in sorghum (Sorghum bicolor (L.) Moench) genotypes with various agronomical traits using SPAR methods. Gene 576: 581-585. http://dx.doi. org/10.1016/j.gene.2015.10.056

Shafiei-Astani B, Ong AH, Valdiani A, Tan SG, et al. (2015). Molecular genetic variation and structure of Southeast Asian crocodile (Tomistoma schlegelii): Comparative potentials of SSRs versus ISSRs. Gene 571: 107-116. http://dx.doi. org/10.1016/j.gene.2015.06.053

Shakeel M, Ilyas M and Kazi M (2013). Evaluation of synthetic hexaploid wheats (derivative of durum wheats and Aegilops tauschii accessions) for studying genetic diversity using randomly amplified polymorphic DNA (RAPD) markers. Mol. Biol. Rep. 40: 21-26. http://dx.doi.org/10.1007/s11033-012-1943-y

Tanksley SD, Young ND, Paterson AH and Bonierbale MW (1989). RFLP mapping in plant breeding: new tools for an old science. Nat. Biotechnol. 7: 257-264. http://dx.doi.org/10.1038/nbt0389-257

Varela ES, Lima JP, Galdino AS, Pinto LdaS, et al. (2004). Relationships in subtribe Diocleinae (Leguminosae; Papilionoideae) inferred from internal transcribed spacer sequences from nuclear ribosomal DNA. Phytochemistry 65: 59-69. http://dx.doi.org/10.1016/j.phytochem.2003.08.005

Vos P, Hogers R, Bleeker M, Reijans M, et al. (1995). AFLP: a new technique for DNA fingerprinting. Nucleic Acids Res. 23: 4407-4414. http://dx.doi.org/10.1093/nar/23.21.4407

Williams JG, Kubelik AR, Livak KJ, Rafalski JA, et al. (1990). DNA polymorphisms amplified by arbitrary primers are useful as genetic markers. Nucleic Acids Res. 18: 6531-6535. http://dx.doi.org/10.1093/nar/18.22.6531

Genetics and Molecular Research 15 (3): gmr.15038721 